\title{
A Review on Thermal Enhanced Heavy Oil Recovery from Fractured Carbonate Reservoirs
}

Eshragh Ghoodjani 凡 Riyaz Kharrat ${ }^{2}$, Manouchehr Vossoughi ${ }^{1}$ and Seyed Hamed Bolouri ${ }^{3}$

${ }^{1}$ Sharif University of Technology, Tehran, Iran

${ }^{2}$ Petroleum University of Technology, Ahwaz, Iran

${ }^{3}$ Shahid Bahonar University, Kerman, Iran

\begin{abstract}
Heavy oil in Middle East fractured carbonate reservoirs account for $25-30 \%$ of the total oil in place in the region. Production of heavy oil from such reservoirs is thought to play an important role in the future of the ever-growing world's energy consumption in which Iran's recoverable heavy oil is more than 85 billion barrels. The offshore Ferdows field in Iran is reportedly on the order of 30 billion barrels of oil and holds perhaps the greatest promise to add significant future carbonate heavy oil production within the region.
\end{abstract}

With depletion of conventional petroleum reserves and increase of hydrocarbon fuel demand, there is no doubt that there will be a tremendous demand on the development of heavy oil reservoirs in the coming decades. Despite its strategic importance, recovery of heavy crude from fractured carbonate reservoirs has found limited applications due to the complexity of such reservoirs. As most of the oil is stored in matrix due to its higher storage capacity than fracture network, reservoir development plans will aim at maximizing the matrix oil recovery. For reservoirs with high recovery factor, minimizing matrix residual oil saturation is a critical issue to extend the life of the reservoir. For reservoirs with low recovery factor, accelerating the production rate is more vital. For each of these reservoir types, different Enhanced Oil Recovery (EOR) methods should be considered and implemented accordingly.

In this study, a comprehensive review is conducted to figure out the feasibility of heavy oil recovery from fractured carbonate reservoirs by use of Cyclic Steam Stimulation (CSS), Steam injection, In-Situ Combustion (ISC), Steam Assisted Gravity Drainage (SAGD), Vapor Extraction (VAPEX) and Expanding Solvent-Steam Assisted Gravity Drainage (ES-SAGD).

Keywords: Fractured carbonate reservoir; Heavy oil; Thermal enhanced oil recovery; SAGD; VAPEX; Steam injection; In-situ combustion

\section{Introduction}

Carbonate reservoirs introduce great challenges due to their complex fabric nature (low matrix permeability, poor effective porosity, fractures) and unfavorable wettability. These challenges are further displayed when combined with increased depth and low grade oil (high density and viscosity). A huge amount of oil is contained in such reservoirs without any technological breakthrough for improving the recovery efficiently [1].

Until recently, heavy oil reserves did not attract much interest. The lowest oil profitability, the low price of the oil barrel in the international market, the difficulties involved in its extraction and its refining, and the large amount of light and medium oils to be explored could not justify the investments. Maturity of light and medium oil fields and the significant increase in oil price placed that source of energy under a new perspective. It is possible to increase heavy oil recovery in some of these reservoirs with the help of enhanced oil recovery processes, thus enhancing oil field productivity and profitability. Screening criteria have been proposed for all enhanced oil recovery (EOR) methods by SPE [2] for conventional reservoirs (Table 1).

The most proven approach to produce heavy-oil reservoirs is through thermal methods, specifically speaking steam injection. Yet, the typical reservoir engineering approach is based on mobility reduction by reducing oil viscosity through effective heating, and by producing oil through viscous and gravity displacement. In carbonate systems, which are fractured in general, introduce rock complexity at different scales, i.e., faults, fissures, micro fractures, vugs, poorly interconnected matrix pore structure, and unfavorable wettability are combined with high oil viscosity. Thus oil recovery from this type of reservoir becomes a real challenge and classic thermal application theories fail to define the process. Main drive mechanisms in fractured reservoirs are shown in Figure 1 [2,3].

Thermal methods (steam injection or in-situ combustion) and nonthermal methods (VAPEX) may be cited as examples of such processes.

Some processes involve both vertical and horizontal wells, as demonstrated by recent progress on certain technologies, such as measuring while drilling (MWD), which improved the success of horizontal wells, reducing any drilling navigation problems. Horizontal wells have shown high efficiency in terms of oil recovery, due to intrinsically larger reservoir contact areas. However, they are still more expensive than vertical wells. Therefore, an economical evaluation is necessary to compare oil earnings and costs before selection of the most appropriate configuration. Example of the technologies that use horizontal wells are: steam assisted gravity drainage (SAGD), expanded solvent with gravity drainage (ES-SAGD) and vapor extraction (VAPEX). These technologies improve the fluid contact

*Corresponding author: Eshragh Ghoodjani, Sharif University of Technology, Tehran, Iran, E-mail: e.ghoodjani@gmail.com

Received February 28, 2011; Accepted April 25, 2011; Published April 28, 2011

Citation: Ghoodjani E, Kharrat R, Vossoughi M, Bolouri SH (2011) A Review on Thermal Enhanced Heavy Oil Recovery from Fractured Carbonate Reservoirs. J Pet Environ Biotechnol 2:109. doi:10.4172/2157-7463.1000109

Copyright: (c) 2011 Ghoodjani E, et al. This is an open-access article distributed under the terms of the Creative Commons Attribution License, which permits unrestricted use, distribution, and reproduction in any medium, provided the original author and source are credited. 
Citation: Ghoodjani E, Kharrat R, Vossoughi M, Bolouri SH (2011) A Review on Thermal Enhanced Heavy Oil Recovery from Fractured Carbonate Reservoirs. J Pet Environ Biotechnol 2:109. doi:10.4172/2157-7463.1000109

Page 2 of 7

\begin{tabular}{|c|c|c|c|c|c|c|c|c|c|c|}
\hline \multirow{2}{*}{$\begin{array}{l}\text { Detail } \\
\text { Table } \\
\text { in Ref. } \\
16\end{array}$} & \multirow[b]{2}{*}{$\begin{array}{c}\text { EOR } \\
\text { Method }\end{array}$} & \multicolumn{3}{|c|}{ Oil Properties } & \multicolumn{6}{|c|}{ Reservoir Characteristics } \\
\hline & & $\begin{array}{l}\text { Gravity } \\
\left({ }^{\circ} \mathrm{API}\right)\end{array}$ & $\begin{array}{l}\text { Viscosity } \\
\text { (cp) }\end{array}$ & Composition & $\begin{array}{l}\text { Oil } \\
\text { Saturation } \\
(\% \mathrm{PV})\end{array}$ & $\begin{array}{l}\text { Formation } \\
\text { Type }\end{array}$ & $\begin{array}{c}\text { Net } \\
\text { Thickness } \\
\text { (ft) }\end{array}$ & $\begin{array}{c}\text { Average } \\
\text { Permeability } \\
\text { (md) }\end{array}$ & $\begin{array}{l}\text { Depth } \\
\text { (ft) }\end{array}$ & $\begin{array}{c}\text { Temperature } \\
\left({ }^{\circ} \mathrm{F}\right)\end{array}$ \\
\hline \multicolumn{11}{|c|}{ Gas Injection Methods (Miscible) } \\
\hline 1 & $\begin{array}{c}\text { Nitrogen and flue } \\
\text { gas }\end{array}$ & $>35 \nearrow \underline{48} \pi$ & $>0.4 \searrow \underline{0.2} \searrow$ & $\begin{array}{l}\text { High percent } \\
\text { of } C_{1} \text { to } C_{7}\end{array}$ & $>40 \nearrow \underline{75} \pi$ & $\begin{array}{c}\text { Sandstone or } \\
\text { carbonate }\end{array}$ & $\begin{array}{l}\text { Thin unless } \\
\text { dipping }\end{array}$ & NC & $>6,000$ & NC \\
\hline 2 & Hydrocarbon & $>23 \nearrow \underline{41} \nearrow$ & $<3 \searrow \underline{0.5} \downarrow$ & $\begin{array}{l}\text { High percent } \\
\text { of } C_{2} \text { to } C_{7}\end{array}$ & $>30 \pi \underline{80}$ & $\begin{array}{l}\text { Sandstone or } \\
\text { carbonate }\end{array}$ & $\begin{array}{l}\text { Thin unless } \\
\text { dipping }\end{array}$ & NC & $>4,000$ & NC \\
\hline 3 & $\mathrm{CO}_{2}$ & $>22>\underline{36} \gamma^{a}$ & $<10 \searrow \underline{1.5}\rangle$ & $\begin{array}{l}\text { High percent } \\
\text { of } C_{5} \text { to } C_{12}\end{array}$ & $>20>\underline{55} \pi$ & $\begin{array}{l}\text { Sandstone or } \\
\text { carbonate }\end{array}$ & Wide range & NC & $>2,500^{\mathrm{a}}$ & NC \\
\hline $1-3$ & Immiscible gases & $>12$ & $<600$ & NC & $>35 \pi \underline{70} \pi$ & NC & $\begin{array}{l}\text { NC if dipping } \\
\text { and/or good } \\
\text { vertical } \\
\text { permeability }\end{array}$ & NC & $>1,800$ & NC \\
\hline \multicolumn{11}{|c|}{ (Enhanced) Waterflooding } \\
\hline 4 & $\begin{array}{c}\text { Micellar/Polymer, } \\
\text { ASP and Alkaline } \\
\text { Flooding }\end{array}$ & $>20>\underline{35}$ & $<35 \searrow \underline{13}\rangle$ & $\begin{array}{l}\text { Light, } \\
\text { intermediate, } \\
\text { some organic } \\
\text { acids for } \\
\text { alkaline floods }\end{array}$ & $>35>\underline{53} \pi$ & $\begin{array}{l}\text { Sandstone } \\
\text { preferred }\end{array}$ & $\mathrm{NC}$ & $>10 \pi \underline{450}$ & $>9,000 \backslash \underline{3,250}$ & $>200 \backslash \underline{80}$ \\
\hline 5 & Polymer Flooding & $>15$ & $<150>10$ & NC & $>50\ulcorner\underline{80}$ & $\begin{array}{c}\text { Sandstone } \\
\text { preferred }\end{array}$ & NC & $>10>\underline{800} x^{b}$ & $>9,000$ & $>200 \unlhd \underline{140}$ \\
\hline \multicolumn{11}{|c|}{ Thermal/Mechanical } \\
\hline 6 & Combustion & $>10>\underline{16} \rightarrow ?$ & $\begin{array}{c}<5,000 \\
\downarrow \\
1,200 \\
\end{array}$ & $\begin{array}{c}\text { Some } \\
\text { asphaltic } \\
\text { component }\end{array}$ & $>50 \nearrow \underline{72} \pi$ & $\begin{array}{l}\text { High-porosity } \\
\text { sand/sandstone }\end{array}$ & $>10$ & $>50^{c}$ & $\begin{array}{l}<11,500 \\
\searrow \underline{3,500}\end{array}$ & $>100>\underline{135}$ \\
\hline 7 & Steam & $\begin{array}{c}>8 \text { to } \\
\underline{13.5} \rightarrow ?\end{array}$ & $\begin{array}{c}<200,000 \\
\downarrow \\
4,700 \\
\end{array}$ & NC & $>40>\underline{66} \pi$ & $\begin{array}{l}\text { High-porosity } \\
\text { sand/sandstone }\end{array}$ & $>20$ & $>200 \underline{2} .540^{d^{\mathrm{d}}}$ & $<4,500 \searrow \underline{1,500}$ & NC \\
\hline- & Surface mining & 7 to 11 & $\begin{array}{l}\text { Zero cold } \\
\text { flow }\end{array}$ & NC & $\begin{array}{c}>8 w t \% \\
\text { sand }\end{array}$ & $\begin{array}{l}\text { Mineable tar } \\
\text { sand }\end{array}$ & $>10^{e}$ & NC & $\begin{array}{l}>3: 1 \\
\text { overburden to } \\
\text { sand ratio }\end{array}$ & NC \\
\hline
\end{tabular}

NC=Not Critical

Underlined values represent the approximate mean or average for current field projects

aSee Table 3 Ref. 16.

b 3 md from some carbonate reservoirs if the intent is to sweep only the fracture system

'Transmissibility $>20 \mathrm{md}-\mathrm{ft} / \mathrm{cp}$

dTransmissibility $>50 \mathrm{md}$-ft/cp

eSee depth.

Table 1: EOR screening criteria for conventional reservoirs [2]

area in the reservoir, the sweep efficiencies and oil production. They may also reduce production costs. Thermal oil recovery methods have proven to be successful in most applications. This can be due to the fact that the oil viscosity is much more reduced by these processes. The chosen method should be carefully evaluated and the analysis should consider physical reservoir parameters, results from similar reservoirs, teamwork experience and reservoir simulations [4-6].

In this research, different methods of enhanced heavy oil recovery from fractured carbonate reservoir are studied. With regard to special characteristics of fractured carbonate reservoirs, study of these methods is important for both screening and implementation.

\section{Enhanced Heavy Oil Recovery Methods}

\section{Cyclic steam stimulation (CSS)}

Cyclic steam stimulation (also known as huff n' puff) was accidentally discovered in Eastern Venezuela in 1959. In this process, steam is injected under high pressure and temperature. The high injection pressure dilates or fractures the reservoir rock and the high temperature helps to reduce oil viscosity. The cyclical injection takes place in three stages: injection time, soaking time, production time.

At the beginning, oil is produced at high rates, which eventually begin to rapidly decrease. The cycle can be repeated several times, whilst still economically viable. This process has as main advantage the fast return during early production. However oil recovery can be as low as 10 or $20 \%$ of the original oil volume [7].

This process can use horizontal and vertical wells [8], depending on the reservoir thickness. The cyclical steam injection has been used in several oil fields with success, like in Alberta, Canada, where oil viscosity is about $100.000 \mathrm{cp}$. In heavy oil fields of Venezuela and Brazil this thermal recovery method has also been used with success. In California, it is used as a first stage before continuous steam injection. Recently, this technology has also been used in horizontal wells.

Dominant mechanisms in heat transfer are: conduction and forced convection during injection, conduction and a minimum convection effect during the soaking period, and counter current of convectionconduction during the production period.

It is important to highlight that in cyclical steam injection the reservoir can contain such viscous oil that can be considered solid. The steam role is "to dissolve that solid" and to allow it to flow through the reservoir [9]. One of the operational conditions in that process is related to the steam required to increase the reservoir temperature to a certain level, taking into account the heat losses.

The soaking time after steam injection can vary from a few days to weeks. There are different opinions regarding optimization of the 
soaking time. In some cases, mechanical and operational considerations will favor a short closing time in the steam injection. The treated well is then put in production and should produce by natural lifting, with its own reservoir energy, during days. This is desirable, because the imposed bottom well pressure tends to prevent water flashing at high temperatures. In the following period, the well will have to be pumped. In some cases, sand control becomes the main operational problem. Frequently, oil rate decreases in subsequent cycles. If the cyclical injection is to be followed by a continuous injection - as observed in recent times - it will be desirable to determine the number of cycles that will maximize the oil recovery for the cyclical injection and steam injection.

Sometimes maximum cumulative oil can be obtained, with 8 or 9 cycles, but the response for a cyclic steam injection varies considerably with the reservoir characteristics. Fractured reservoirs studies show the importance of capillary imbibition on the process. Fracture frequency has very minimal effect in the process. As an example, for highly tilted and thick California reservoirs, gravity drainage is dominant and many cycles are possible, since less viscous, warm oil continue to flow down in the direction of the producing well. Regardless of the reservoir type, the cyclic injection becomes usually less efficient with increasing number of cycles. This fact is evident in several production statistics. The average and maximum rates as long as total oil recovery decrease in the last cycles [10].

\section{Continuous steam injection}

The injection of steam as a recovery method for heavy oil has been used for many years. In this process steam is continuously injected in one or more vertical wells, and the oil is pushed away to producing wells. Since this process requires injectors and producers, a larger area inside of the reservoir is embraced, and oil recoveries higher than those provided by cyclical steam injection are obtained. Oil recovery in this process can reach up to $50 \%$ or more, but thermal efficiency is lower than in cyclical steam injection. Heating of the oil has the following effects: Thermal expansion, Viscosity reduction, Activation of solution gas drive, Distillation (thermal cracking) and potentially wettability modification [11].

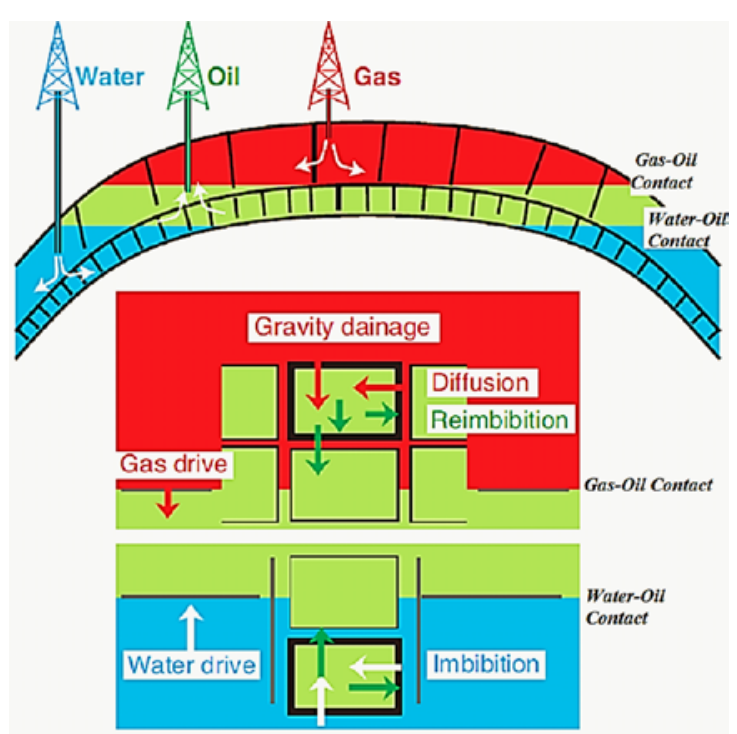

Figure 1: Main drive mechanisms in fractured reservoirs [2].

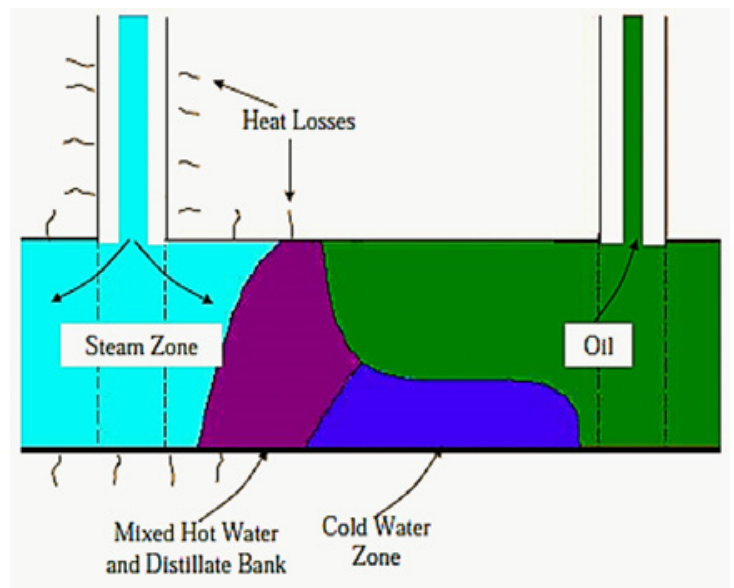

Figure 2: Steam injection scheme taking acount gravity [12]

Gravity drainage is one of the most important mechanisms by which oil is recovered from fractured reservoirs. Steam injection in fractured carbonates containing heavy oil is considered. The viscosity effect here is most important, improving Gas-Oil Gravity Drainage (GOGD) rates to commercial values. Another steam based EOR method that used in fractured carbonate reservoirs is Thermally Assisted Gas-Oil Gravity Drainage (TA-GOGD). In TA-GOGD process, steam is injected into the reservoir and heats the rock matrix blocks through the higher permeability fracture network and improves oil recovery principally by reducing the oil viscosity and thus increasing the rate of gravity drainage through the matrix. TA-GOGD can be summarized by the statement "steam in gives oil out", so the major development choice is the selection of the appropriate steam rate for the development. The optimum steam can be selected on a base case based upon one or more economic parameters. However, given the range of uncertainties due to fracturing, a risked economic parameter approach was taken using the scenarios of low case fracturing, base case fracturing and high case. Steam injection scheme taking account gravity is shown in Figure 2 $[12,13]$.

Recent projects for oil recovery have proposed the combination of vertical and horizontal wells, but some technical problems still exist such as minimization of the impact of the gas cap and of water influx. The methods of continuous and cyclical steam injection are frequently combined and used [14], whereby wells produce oil through cyclical stimulation before the beginning of continuous steam injection. In the case of very viscous oils, stimulation prior to continuous injection is essential to obtain flow communication between injectors and producers. This communication can be established through the creation of fractures among the wells, which can be done by injecting steam at sufficiently high pressures.

Oil recovery in this process depends on several factors [15], such as viscosity decrease, oil swelling and, most importantly, the reduction of oil saturation in the steam zone. The displacement efficiency is increased by the heat to the proportion that more oil flows. Oil saturations behind the steam zone can be as low as $5 \%$.

In the steam displacement experiments in fractured models, it was found that the steam enters into the fracture or the matrix depending on the steam rate. If the capillary number exceeds the critical, steam can displace the fluids in the matrix, otherwise it moves into the fracture only. Effect of fracture intensity on oil recovery of steam injection 
is shown in Figure 3. This Figure shows that in continuous steam injection, higher fracture density results in higher early production rate, but as the fracture's oil depleted, oil production from matrix blocks are almost the same [16].

\section{In-situ combustion (ISC)}

This process was first tested in Pennsylvania in the early 1950s. Over 200 in situ combustion field tests and commercial operations have been carried out worldwide, but only a few are still in operation. The in situ Combustion method begins with the injection of heated air into the oil reservoir. Heat is generated as a result of oil oxidation, increasing the temperature. Continuing the Oxidation, the temperature eventually reaches the so-called "ignition point", when the combustion is established. At that point it is necessary to inject cold air to provide continuity to the process. The combustion front displaces any trapped reservoir fluids (including injected gases and those resulting from combustion), up to the producing well. In this process care should be taken with parameters such as combustion temperature and gravitational segregation of the gases that leads to early combustion zone breakthrough in the producers.

In Iran, carbonate rocks are bearing the most of heavy crude oils. Running in-situ combustion process in carbonate reservoirs might be risky due to the probability of decomposition of the rock and production of carbon dioxide at high temperatures. While decomposition occurs in dolomite or limestone, the rock will change in to a powder like material that will definitely cause plugging. The effect of fractures could be sometimes very dramatic. Since fractures may lead to oxygen breakthrough and failure of the process. Besides all these concerns economy and instrumentation requirements are other considerations that should come in to account. Usually, long term investigations and studies are conducted before choosing a reservoir for this process. One of the most important parts of these studies is the feasibility study.

Before field implementation, feasibility studies are carried out in order to understand whether the process is possible on the rock and oil of the field. Combustion tube tests and other thermo metric tests like thermo gravimetric analyzer (TGA) and differential scanning calorimeter (DSC) are usually used to test the feasibility of a process. Some of these tests show the feasibility of using in-situ combustion in heavy oil carbonate reservoirs. Akkutlu and Yortsus [17] the most significant operation problems affecting recovery from heavy oil reservoirs using vertical-vertical well pattern in situ combustion are:

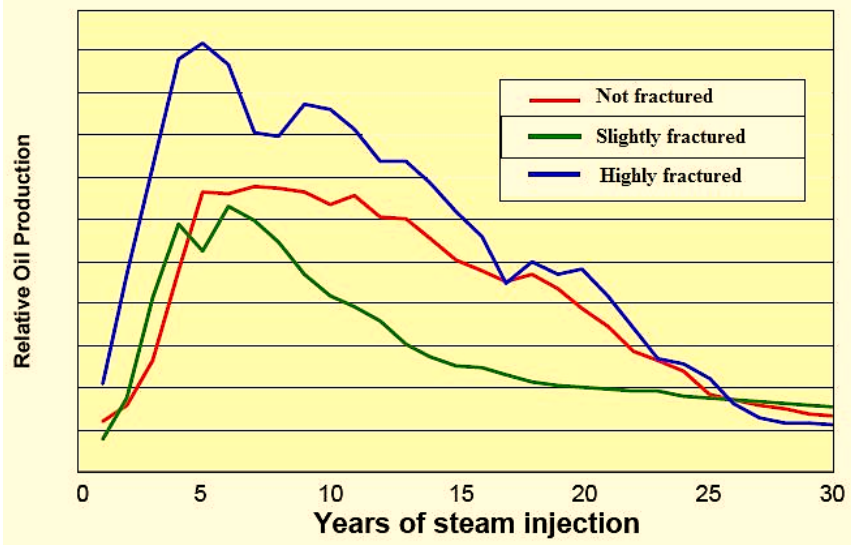

Figure 3: Effect of fracture intensity on oil recovery of steam injection [15]. (a) Gravity segregation, or gas overriding, due to the difference between the gas and oil densities. (b) Channeling, due to the unfavorable rock heterogeneity. (c) Unfavorable gas/oil mobility ratio. THAI 'Toe-toHeel Air Injection' is EOR process which integrates in situ combustion and advanced horizontal well concepts [18]. In this process a horizontal well is used as oil producer at the bottom of the reservoir, and a vertical well is employed as air injector at the top and near the end (toe) of the horizontal well. The air injected into the vertical well generates the combustion front that burns part of the oil and releases heat. The heat reduces the oil viscosity inside the reservoir, which flows to the horizontal well at the bottom, due to gravity. The combustion front sweeps from the end of the horizontal producer (toe) up to the heel, leading to recoveries of oil up to $80 \%$. Investigations [19] reveals that during the first hours of the operation the oil recovery from the fractured medium is higher due to ease of production from fracture while later production from the fractured medium will be limited to the production of oil from the matrix which is controlled by diffusion of the oxygen into the matrix and expansion of the oil from the matrix. On the other hand, early higher average temperature in the fracture compared to the unfractured block is an indication of higher amount of crude oil being burned during the combustion within the fracture media than that during the combustion in the matrix block occurring later in time.

The higher rate of the front propagation in the fracture, as opposed to that in the matrix, causes the matrix to be preheated forward of its own combustion front. This preheating reduces oil viscosity and oil is transferred to the lower parts because of gravity drainage. As a result, low amount of oil will be present in the face contacting the matrix combustion front and thereby less coke will be generated. Lower coke deposition means lower front temperature. This reduces the average temperature and causes lower coke deposition. As a result, lower ultimate oil recovery would be achievable in the fractured reservoirs. Less opportunity is given for oxygen to diffuse into the matrix for higher fracture spacing and as a result the oil recovery is reduced and lower system temperature is attained [20].

\section{Steam assisted gravity drainage (SAGD)}

Steam-Assisted Gravity Drainage (SAGD) and its variations are technologies that have been recently considered as more effective in the recovery of heavy oil and bituminous sands [21]. The method involves two horizontal parallel wells vertically separated by a short distance, where the top well serves as steam injector and the bottom well picks up reservoir water, condensed water and heated oil. Gravity is the acting force in this process. When steam is continually injected at the top well, oil is heated up and forms a steam chamber that grows up and towards the surroundings. The temperature inside the steam chamber becomes essentially equal to the temperature of the injected steam. It is noticed that steam condenses at the interface with cold oil and heat is transferred to the oil. Then, heated oil and condensed water drain by gravity, until the producing horizontal well located at the bottom of the reservoir.

In this process the steam chamber begins to grow upward approaching the reservoir top and later extends horizontally [22]. It may keep growing up with continuous steam injection. If the injector well is located very close to the producer, at the base of the reservoir, the vapor will tend to go up, and condensed fluids will go down. Therefore, the trend of the steam to flow directly to the producing well will be reduced. As a result, the SAGD process provides the drainage of a large area of the reservoir. This process depends mainly on the difference of 
densities between the steam chamber and the liquid phase, and also on the vertical effective permeability of the reservoir [23,24].

The consequences of this theory $[25,26]$ refer to the growth of the steam chamber, which is necessary in oil production. In other words, the oil production happens while steam is injected, and the higher the steam temperature the higher will be the oil temperature, thus yielding higher oil production.

Due to the fact that oil production in the SAGD process depends basically on gravity drainage, wells with large lengths guarantee good oil productions and, as a consequence, the project profitability is augmented. Compared to conventional steam injection, SAGD presents a very significant advantage: in continuous injection, oil is pushed to a cold region, and its mobility is low since it stays ahead of the steam zone. However, in the SAGD process, oil is drained in a flow which is approximately parallel to the steam chamber, still arriving at the producer at warm temperatures, and, consequently, with high mobility. Furthermore, the tendency of the steam to create a path through the oil is used in favor of the process $[8,9]$.

In addition to the benefits of the gravity effects, this process foresees more systematic steam coverage of the reservoir, provides a larger contact of oil volume and keeps the oil warm during production. The SAGD performance can be significantly affected by the selection of the geometry and by the operational parameters [27]. Examples of this can be: vertical distance between wells, horizontal length of both injector and producer wells, presence of shale, permeability, oil viscosity, aquifer characteristics, gas cap, and others.

SAGD in Sandstone heavy oil Reservoirs has been characterized quite well over the last years. However, there is huge carbonate heavy oil reserves in the world which their production can be enhanced by thermal recovery processes, especially by this process. Investigations [28] show that matrix permeability is expected to play important role in the process. Vertical fractures improve oil recovery compare to the disastrous effect of horizontal fractures. Vertical fractures density increase, improves SAGD oil recovery but horizontal fractures density increase restricts steam chamber development in reservoir. Near injection well horizontal fractures have less effect on recovery than far ones. In networked fractures, vertical fractures improve recovery achievable by horizontal fractures [29].

\section{Vapor extraction (VAPEX)}

The vapor extraction (VAPEX) process, introduced by Butler and Mokrys as an alternative in-situ EOR method to SAGD, has been studied theoretically and experimentally in conventional, non-fractured systems. This process employs hydrocarbon vapors to extract bitumen or heavy oil, has been under development in recent years. The process involves the injection of solvent vapors or solvent mixtures containing non-condensable gas into the reservoir. The crude oil becomes diluted by dissolved solvents and drains downwards to the production well by gravity. One of the features of the VAPEX, that the stem processes do not have, is the improved quality of the produced oil due to the effect of de-asphalting [30].

This process is found to be promising alternative to thermal processes. On the other hand, considerable heavy oil resources are located in low-permeable, fractured carbonate reservoirs. However, little information is available on the performance of the VAPEX process in fractured reservoirs. The preliminary studies on the VAPEX process in fractured systems included a single block matrix surrounded by fractures. It was found that [31] due to differences in matrix and fracture permeability in the fractured system, the solvent first spreads through the fractures and then starts diffusing into matrix from all parts of the matrix. Thus, the solvent surrounds the oil bank, and oil rather than the solvent chamber forms and shrinks as the process proceeds. Also, it was found that the diffusion process becomes important and higher recoveries are obtained at low injection rates, provided sufficient time is given to the process.

For a specific system, an optimization procedure is necessary to find the optimum solvent injection rate [32] from technical and economical points of view. Parameters that should be taken into account include dimensions of the system, rock and fluid properties, and breakthrough time of solvent. The higher diffusion coefficient can improve the final recovery factor, while the solvent penetration into the oil phase occurs faster.

Previous simulation studies on the VAPEX process in fractured systems included single-block and multiple-block systems in which matrix blocks were surrounded by fracture networks. Results of these studies showed that the fracture network provides large area for solvent to distribute in the reservoir. This can be encouraging in application of the VAPEX process in low permeability carbonate reservoirs, where the fracture network provides potential flow paths for solvent flow into reservoir. In general, fractures are likely to enhance the process by improving the contact between solvent and oil contained in the matrix blocks. Also, fractures are likely to enhance the process by increasing the overall vertical permeability in the system. The important concern in this process when applied to fracture reservoirs is early solvent breakthrough through fracture network without efficient contact with heavy oil, which can reduce process efficiency and let the solvent escape out of the reservoir. Presence of thief zones in the reservoir can also affect the process, in that the solvent will flow out of reservoir without sufficient contact with heavy oil. The summery of previous investigations on VAPEX in fractured reservoirs is mentioned below: [33-36].

- Fracture network enhances the VAPEX process by improving the contact between solvent and oil contained in the matrix blocks.

- The fracture network reduces the instabilities in the system pressure and damps pressure surges in the system during the VAPEX process.

- The solvent traverse between fracture networks delays the onset of solvent breakthrough and provides more residence time for the solvent to be in contact with heavy oil.

- Under controlled conditions, existence of fracture network in low-permeability systems contributes and improves heavy oil production by VAPEX process.

- The well location is a critical issue when applying the VAPEX process in fractured systems and affects the oil and gas production.

- The higher fracture frequency causes higher oil recovery as shown in Figure 4 [35].

\section{Expanding solvent-steam assisted gravity drainage (ES- SAGD)}

This process is a combination of solvent and steam injection that take advantage of the heat provided by steam and the miscibility offered 


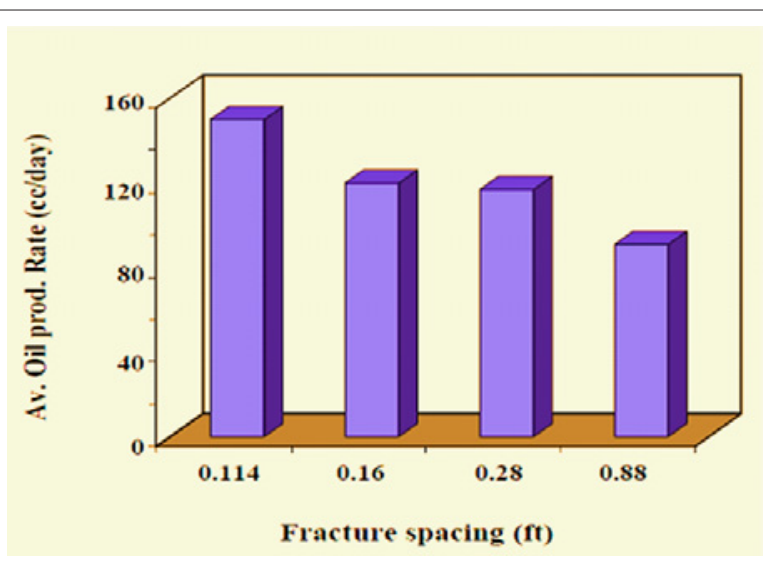

Figure 4: Effect of fracture spacing on oil production of VAPEX process [35].

by the solvent [37]. This is a novel process that has already been tested in oil fields, resulting in improvement of oil rate production and steam oil ratio (SOR). This process requires less energy than conventional SAGD.

The basic concept of ES-SAGD is to inject a light hydrocarbon additive at low concentration together with steam, in a process whereby the dominant force is gravity. The additive is selected in such way that can evaporate and condense at water conditions. In this way, solvent can condense with steam close to the steam chamber interface. The added hydrocarbon is injected in the vapor form. The condensed solvent dilutes in oil and, aided by the heat, reduces the oil viscosity in the reservoir [37].

The ES-SAGD process was developed to improve the energy efficiency and oil drainage of SAGD. In this process, a small amount of solvent with a vaporization temperature closely matching that of steam is co-injected with steam. As the solvent condenses with the steam along the boundary of the gas chamber, it dissolves in the bitumen thereby reducing its viscosity and increasing oil recovery rates. Use of solvent with steam during the pre-heat may enhance the subsequent ES-SAGD as the solvent can dissolve in the oil at the higher pressures and lower temperatures during the pre-heat [12]. The solvent can be injected intermittently with the steam or co-currently with the steam.

Previous studies [24,35] were shown that vertical fractures improve oil recovery, but horizontal fractures restrict steam chamber development. Therefore vertical higher fractures density, improves oil recovery. Fracture network enhances the miscibility process by improving the contact between solvent and oil contained in the matrix blocks.

\section{Conclusion}

Thermal oil recovery methods are used mainly in heavy oils or bituminous sands with the intention of reducing oil viscosity in the reservoir, increasing its mobility and allowing better displacement to the producing wells. The selected process always depends on reservoir characteristics, reservoir fluids, area and experience from similar reservoirs. Due to its complexity, numerical analyses, reservoir modeling and profitability analyses are always required in order to determine which process is more efficient in minimizing the amount of injected fluids.

Heavy oil production profitably by steam injection is a reality. Steam injection variations are being developed for reservoirs that were considered unsuitable for steam injection only a short time ago. This has been possible because of advances in horizontal well drilling, and powerful computers. Steam injection is costly, and careful design and heat management are the keys to economic success. In situ combustion is a special process that may be applicable sometimes where steam is not applicable (e.g. thin and deep formations, bottom water, etc.).

\section{References}

1. Briggs PJ, Beck DL, Black CJJ, Bissell R (1992) Heavy Oil from Fractured Carbonate Reservoirs. SPE Reservoir Engineering 7: 173-179.

2. Taber JJ, Martin FD, Seright RS (1997) EOR Screening Criteria Revisited- Part 1: Introduction to Screening Criteria and EOR Field Projects. SPE Reservoir Engineering. 12: 189-198.

3. Farouq A, Meldau PB (1983) Improved oil recovery. Chapter VII Interstate Oi Compact Commission Oklahoma City Oklahoma.

4. Nasr TN, Ayodele OR (2005) Thermal techniques for the recovery of heavy oi and bitumen. SPE International Improved Oil Conference in Asia Pacific held in Kuala Lumpur Malaysia 5-6 December technical paper SPE 97488.

5. Farouq A (2003) Heavy oil-ever more mobile. Journal of Petroleum Science \& Engineering 37: 5-9.

6. Briggs PJ, Fulleylove RJ, Wright MS, Baron RP (1988) Development of heavy oil reservoirs. Fifth SPE Middle East oil show held in Manama Bahrain March 7-10 technical paper SPE 15748 40: 206-214.

7. Batycky JP, Leaute RP, Dawe BA (1997) A Mechanistic Model of Cyclic Steam Stimulation. Paper SPE 37550 Proc Thermal Operations \& Heavy Oi Symposium Bakersfield CA 323-336.

8. Escobar MA, Valera RE, Perez RE, Lagoven SA (1997) A Large Heavy Oi Reservoir in Lake Maracaibo: Cyclic Steam Injection Experiences. Paper SPE 37551 Proc Thermal Operations \& Heavy Oil Symposium Bakersfield CA 337347

9. Gonzalez R, Brunings C, Toussaint L, Corpoven SA (1997) ESPs in Cyclic Steam Injection Wells paper SPE 39084 Proc Fifth Latin American and Caribbean Petroleum Engineering Conference and Exhibition Rio de Janeiro.

10. Trebolle RL, Paz MC, Martinez DE, Lagoven SA (1993) Parametric Study of the Design Factors for Cyclic Steam Injection in Lake Maracaibo Oil Fields. SPE 25810 Proc Thermal Operations \& Heavy Oil Symposium Bakersfield CA 331-341.

11. Britton MW, Martin WL, Leibrecht RJ, Harmon RA (1982) The Street Ranch Pilot Test of Fracture-Assisted Steam flood Technology. Paper SPE 10707 presented at SPE California Regional Meeting San Francisco CA March 24-26.

12. Chierici GL, Della Canne A, Properzi O (1985) Steam Drive in a Fractured Carbonate Pilot. Presented at the European Meeting on Improved Oil Recovery Rome Italy.

13. Dreher KD, Kenyon DE (1986) Heat Flow during Steam Injection into a Fractured Carbonate Reservoir. Paper SPE 14902 presented at the SPE/DOE Symposium on Enhanced Oil Recovery Tulsa April 20-23.

14. Pooladi-Darvish Mehran, Farouq Ali SM (1994) Steam Heating of Fractured Formations Containing Heavy Oil: Basic Premises and a Single-Block Analytical Model. Paper SPE 28642 presented at the SPE Annual Technical Conference and Exhibition New Orleans LA September 25-28.

15. Bahonar M, Ataei A, Masoudi R, Mousavi Mirkalaei SM (2007) Evaluation of Steam Injection in a Fractured Heavy-Oil Carbonate Reservoir in Iran. SPE 105299

16. Van wunnik JNM, Wit K (1992) SPE Reservoir Engineering page 75.

17. Akkutlu IY, Yortsus YC (2002) The Effect of Heterogeneity on In Situ Combustion: Propagation of combustion Fronts in Layered Porous Media. SPE Paper 75128 presented at the SPE/DOE Symposium on Improved Oil Recovery Tulsa USA.

18. Fatemi SM, Kharrat R, Vossoughi S (2008) Feasibility Study of In-Situ Combustion (ISC) in a 2-D Laboratory Scale Fractured System Using a Thermal Reservoir Simulator. Presented at 2nd World Heavy Oil Congress Edmonton Canada. 
Citation: Ghoodjani E, Kharrat R, Vossoughi M, Bolouri SH (2011) A Review on Thermal Enhanced Heavy Oil Recovery from Fractured Carbonate Reservoirs. J Pet Environ Biotechnol 2:109. doi:10.4172/2157-7463.1000109

19. Tabasinejad F, Karrat R, Vossoughi S (2006) Feasibility Study of In-Situ Combustion in Naturally Fractured Heavy Oil Reservoirs. SPE 103969.

20. Mostafavi SV, Kharrat R, Razzaghi S (2007) Feasibility Study of In-Situ Combustion in a Carbonate Reservoir. SPE 105576.

21. Thomas S (2008) Enhanced Oil Recovery-An Overview. Oil Gas Sci TechnolRev IFP 63: 9-19.

22. Akin S, Bagci SA (2001) Laboratory Study of Single-well Steam-Assisted Gravity Drainage Process. J. Petrol Sci Eng 32: 23-33.

23. Barillas JLM, Dutra TV, Mata W (2006) Reservoir and operational parameters influence in SAGD process. J Petrol Sci Eng 54: 34-42.

24. Chen Q, Gerritsen MG, Kovscek AR (2008) Effects of Reservoir Heterogeneities on the Steam-Assisted Gravity Drainage Process. SPE 109873 SPE Reservoir Evaluation \& Engineering 11: 921-932.

25. Bagci AS (2006) Experimental and Simulation Studies of SAGD Process in Fractured Reservoirs. Presented at SPE/DOE Symposium on Improved Oil Recovery Tulsa Oklahoma SPE paper 99920.

26. Shin H, Polikar M (2007) Review of Reservoir Parameters to Optimize SAGD and Fast-SAGD Operating Conditions. PETSOC 07-01-04 Journal of Canadian Petroleum Technology 46: 35-41.

27. Butler RM (2001) Application of SAGD, related process growing in Canada. Oil and Gas Journal 74-78.

28. Ito Y, Suzuki S, Hirata T (1999) Effect of Reservoir Parameters on Oil Rates and Steam-Oil Ratios in SAGD Projects. 9th UNITAR, Beijing.

29. Sedaee Sola B, Rashidi F, Amir-Kabir (2006) Application of the SAGD to an Iranian Carbonate Heavy-Oil Reservoir. SPE 100533
30. Butler RM, Mokrys IJ (1991) A New Process (VAPEX) for Recovering Heavy Oils using Hot Water and Hydrocarbon Vapour. Journal of Canadian Petroleum Technology 30.

31. Butler RM, Mokrys IJ (1998) Closed-Loop Extraction Method for the Recovery of Heavy Oils and Bitumen Underlain by Aquifers: The VAPEX Process. Journal of Canadian Petroleum Technology 37.

32. Butler RM, Mokrys IJ, Das SK (1995) The Solvent Requirements for VAPEX Recovery. SPE 30293 Presented at the International Heavy Oil Symposium Calgary Alberta Canada June 19-21.

33. Boustani A, Maini BB (2001) The Role of Diffusion and Convective Dispersion in Vapor Extraction Process. Journal of Canadian Petroleum Technology 40 68-78.

34. Butler RM, Jiang Q (2000) Improved Recovery of Heavy Oil by VAPEX with Widely Spaced Horizontal Injectors and Producers. Journal of Canadian Petroleum Technology 39: 48-56.

35. Azin R, Kharrat R, Ghotbi C, Vossoughi S (2005) Applicability of the VAPEX Process to Iranian Heavy Oil Reservoirs. SPE 92720 Presented at the 14th SPE Middle East Oil \& Gas Show and Conference Bahrain 12-15 March.

36. Feali M, Kharrat R (2008) Feasibility Study of the Cyclic VAPEX Process for Low Permeable Carbonate Systems. International Petroleum Technology Conference held in Kuala Lumpur Malaysia 3-5 December IPTC 12833.

37. Bryan Orr, SPE, Nexen Inc (2009) ES-SAGD: Past, Present and Future. Paper Contest at the SPE Annual Technical Conference and Exhibition held in New Orleans USA SPE-129518-STU. 